\title{
Engaging interaction and long-term engagement with WhatsApp in an everyday life context: exploratory study
}

Juan A. Martínez ${ }^{1}$ \& Ian Ruthven ${ }^{2}$

${ }^{1}$ Universidad Complutense de Madrid, Spain

${ }^{2}$ University of Strathclyde, Glasgow UK

This is a peer reviewed, accepted author manuscript of the following in-press research article: Martínez, J. A., \& Ruthven, I. (Accepted/In press - 19 December 2020). Engaging interaction and long-term engagement with WhatsApp in an everyday life context : exploratory study. Journal of Documentation. https://doi.org/10.1108/JD-07-2020-0115 


\title{
Engaging interaction and long-term engagement with WhatsApp in an everyday life context: exploratory study
}

\begin{abstract}
Purpose

The aim of this exploratory study is to analyze if the most used factors related to the engaging interaction and long-term engagement with online applications can be applied to WhatsApp in a context of everyday life and to investigate what parameters would best describe the engagement with WhatsApp in this context.

\section{Design/methodology/approach}

A qualitative method was employed to explore the cognitive, emotional, and behavioral factors that mainly comprise the experience of a user with an online application, both at a point in time and over time. Data from thirty semi-structured interviews and questionnaires from six group chats were collected and analyzed. The sample was made up of people from 13 to 58 years old.
\end{abstract}

\section{Findings}

Findings suggest that the factors used in this study to evaluate long-term engagement and engaging interactions with WhatsApp are relevant, except for cognitive factors related to engaging interactions, indicating that the cognitive point of view is more difficult to apply in the engaging interaction analysis. Other attributes related to information retrieval are suggested, best suited to the informative use of this tool.

\section{Originality/value}

Long-term engagement studies are scarcer concerning Mobile Instant Messaging applications. Regarding engagement interaction, its analysis focusing on WhatsApp has not been approached. This study suggests the convenience of using parameters related to information to evaluate the engaging interaction, according to the informative use of the application.

\section{Keywords}

WhatsApp, Engaging interaction, Long-term engagement, Emotional aspects, Cognitive aspects, Behavioral aspects, Qualitative methods

\section{Paper type}

Research paper 


\section{Introduction}

The increasing success of Social Networking Sites (SNS) and Mobile Instant Messaging (MIM) applications has sparked interest among researchers in finding out which are the reasons for using these applications, what leads the population to include Facebook or WhatsApp in their daily use applications. The reason for this interest lies in the fact that a further dive in the causes for the employment of these tools leads to the technical improvement of these applications and, in consequence, provides greater business profits for their developers. From an academic standpoint, research in this field allows us to reach a better understanding of the cognitive, emotional and social mechanisms involved in their use, and their relation to user behavior.

Recently, the concept of engagement attempts to unify traditional criteria -such as usability, based on system performance--and other subjective factors such as its sensory appeal, or the emotional or social aspects involved in the use of new technologies (O'Brien, 2011). This conception of engagement allows, on the one hand, the analysis of an engaging interaction, that is, the factors that lead the user to perceive as a positive experience each time they interact with the application in only one session, at a specific point in time. On the other hand, it allows the study of a long-term engagement, alluding to the causes that justify loyalty to the application over time (Lalmas et al., 2014).

The attributes of long-term engagement or an engaging interaction have been studied focusing on many activities (Brown and Cairns, 2004; Reynolds and Chiu, 2016; Hamari et al., 2016; Arapakis et al., 2014a; Lehmann et al., 2017; Haywood and Cairns, 2005; Fantoni et $a l ., 2012)$. In the same way, long-term engagement has been approached in relation to SNS applications (Korhan and Ersoy, 2016; Nwokedi, 2019), but this kind of studies are much scarcer concerning MIM applications (Dhir et al., 2018; Sullivan and Koh, 2019). Regarding the analysis of engaging interactions, WhatsApp's case specifically has not been approached. It is important to fill that gap considering WhatsApp is the third most important social media application by number of users, after Facebook and YouTube (Statista, 2020).

The study of engagement with WhatsApp in Spain is particularly interesting, since it is the most used social media application there, even over top SNSs in other countries, such as Facebook in the United States or YouTube in the United Kingdom (Fundación Telefónica, 2019). Moreover, the analysis of engagement in an everyday life context has hardly been 
addressed (Fenech, 2015). Filling this gap is important considering that the high level of daily use of these applications causes even traditional information services and systems to progressively be substituted by more informal ones, such as social media (Julien and Michels, 2004).

The purpose of this exploratory study, therefore, is to analyze the characteristics of WhatsApp that justify both engaging interaction and long-term engagement of users with this application in Madrid (Spain) and in the context of everyday life. For that, we will begin by introducing the most significant and frequently used theories in the literature when analyzing the cognitive, affective and behavioral components of both long-term engagement and engaging interaction, with the purpose of finding out their common indicators, although many of these theories include factors from various components. Once these engagement indicators are spotted, while verifying at the same time that they have been used in the social media field, the purpose of this exploratory study will be to analyze if said factors can be applied to WhatsApp in an everyday life context and, in consequence, which component or components are more appropriate to evaluate both long-term engagement and engaging interactions in WhatsApp in an everyday life context.

\section{Literature Review}

Concept of engagement: Theoretical framework

Bennett, Butler and Whiteside were some of the first to apply the term usability to the development of a user friendly interaction with machines at the end of the 80s of the 20th century (Bennett et al., 1989). Around the middle of the 90s of the 20th century, usability was already considered the main factor in software quality, and therefore, a necessary requirement for the commercial success of computer applications. The quality of any computer-based interactive tool relied greatly on the user interface. That is why usability focused on its characteristics, especially on being readily comprehended, quickly learned and reliably operated. Conceived this way, the term usability was closely related to the interface elements that facilitated interaction between the users and the software applications (Nielsen, 1993).

Among the main aspects related to usability conceived as such, the layout and appearance of screens on the one hand, and control on the other hand, stood out. Regarding the layout and appearance of the screen, aspects such as the placement of information, presentation of data, and spatial relationships among elements, among others, were analyzed (Tullis, 1988). Control, in turn, approached aspects concerning the mouse or the keyboard, as 
well as the appearance and behavior of buttons and scrollbars, or the error handling, so the user could be the one to guide the operations during the interaction at all times (Olsen, 1992). Usability, therefore, focused on hardware and software, on the computer system, as the main factor to improve the interaction between the user and the applications.

However, at the end of the 80s of the 20th century, some voices start coming forward warning about the need to expand concepts related to software quality beyond usability, bringing attention to the experience applications evoke in consumers and the overcoming of user-friendliness (Carroll and Thomas, 1988). That is how concepts such as "emotional usability" or "behavioral usability" in the Human-Computer Interaction (HCI) community arise (Logan, 1994). The claim for a broader approach in the design and evaluation of software quality causes the emergence of the concept "user experience" that emphasizes the user over the system (Whiteside et al., 1988).

During the 90s of the 20th century, the concept of engagement or engaging activity begins to settle as an equivalent to a seductive and fulfilling experience (Skelly et al., 1994), and the benefits of achieving pleasurably engaging interactions begin to be acknowledged (Laurel, 1991). Nowadays the concept of User Engagement (UE) addresses the level in which users continuous and enthusiastically use a technological tool. It manifests differently depending on the environment, which considerably hinders not only its definition (Attfield $e t$ al., 2011), but also the development of specific indicators adapted to each field and their evaluation.

Ever since their beginnings, analyses of engagement or engaging interactions usually tackle different aspects simultaneously, highlighting cognitive, affective and behavioral aspects over experience (Jacques et al., 1995; Kappelman, 1995). Throughout the 21st century this approach is consolidated, so that the design and evaluation of engaging software classifies users' actions when interacting with applications in three major groups: cognitive (thoughts, perceptions or any other mental activity when doing the activity or using the tool or application), emotional or affective (feelings aroused by the system use or activity) and behavioral (physical actions performed by the individual while carrying out the activity or using the system). Therefore, thinking, feeling and doing are the three major aspects of engaging interaction between the consumer and the product (Overbeeke et al., 2002). Similarly, in recent years the analysis of engagement throughout the whole lifespan of the software is divided in two main phases: long-term engagement and engaging interaction. Long-term engagement tackles the factors that justify loyalty to the software in users over time -also named continuance intention, continuance usage, continuation of use or continued use (Dhir et al., 2018)-, while the analysis of an engaging interaction addresses what makes each specific use of the application a positive experience that drives the user to repeat it (Arapakis et al., 2014b; Lalmas et al., 2014).

In conclusion, the studies on engagement have addressed a variety of factors that contribute to the experience and continuity of a favorable attitude towards the use of a specific application. These numerous factors consider aspects focused on the user (attention, motivation, for example), or the system (aesthetic appearance, control or feedback, among 
others). This study approaches the aspects focused on the user, relegating the factors related to the system, since in the specific context of instant messaging applications these factors have much less influence.

In turn, attributes related to the user can be summarized in what users do, think or feel whenever they interact with the system. It is frequent, however, for every theory on engagement to simultaneously include various cognitive (mental activities or thoughts), affective (feelings or emotions) and behavioral (actions or behaviors) factors in its development. As mentioned in the introduction, in this study we will begin by elucidating which are the common factors in the main theories regarding each cognitive, affective and behavioral component, although many of said theories include factors that correspond to multiple components.

This study on engagement focuses on social media, defined as a form of computer-mediated communication that encompasses applications and web sites that facilitate sharing and exchanging user-generated content by creating digital environments dedicated to interaction and networking (Kapoor et al., 2018; Kaplan and Haenlein, 2010). In our case, there are to types of platforms of interest: Social Networking Sites (SNS) and Mobile Instant Messaging (MIM) services. SNSs are web-based services that allow individuals to construct a public or semi-public profile and share digital content with other users within the system (Boyd and Ellison, 2007). Facebook, Twitter and Instagram stand out among the most popular SNSs. MIM services, however, allow individuals to exchange usually brief textual messages through mobile phones between two or more members of a group (Watts and Wyner, 2011). They are particularly useful to stay in touch with people who are very close or with communities that prefer private or closed communication spaces over public or semipublic platforms (Taipale and Farinosi, 2018). Among the most popular MIM applications we can name WhatsApp, WeChat or Line. As mentioned in the introduction, the aim of this exploratory study is to test the application of the factors present in engagement theories to WhatsApp in an everyday life context, indicators also used in the field of social media.

\section{Cognitive perspective of engagement}

Starting with cognitive aspects, many theories have been used to approach the study of both long-term engagement and engaging interaction. We will now summarize the most notable ones, highlighting the main factors that justify users' loyalty to a particular tool or application. Subsequently, we will tackle the most significant useful approaches in the analysis of the level of involvement reached by users when they are using said applications.

The Theory of Reasoned Action (TRA), used to predict consumer behavior, claims behavior intention is originated by individual attitudes and beliefs, and by Subjective Norm (SN), alluding to social pressure (Fishbein and Ajzen, 1975). The Theory of Planned 
Behavior (TPB), which emerged in the field of computer-mediated communication, suggests that the attitude of the user towards a certain behavior, the SN (perception of others' beliefs) and and the perceived behavioral control (PBC) - as the perceived ease of engaging in a certain behavior considering past experiences-, affect his or her behavioral intentions (Ajzen, 1991),

Taking TRA and TPB as reference, the Technology Acceptance Model (TAM) has become one of the most popular ones to analyze the costumer long-term engagement to a certain information technology. The initial theoretical framework justifies the continued use according to perceived usefulness (PU), or the perception that the use of a system will enhance his or her job performance, and the perceived ease of use (PEOU), i.e., the perception that the system use is free of effort (Davis, 1989). Subsequent extensions of the initial theory have added other aspects, such as perceived enjoyment (PE) in TAM3, referring to the level of enjoyment perceived from system use (Venkatesh and Bala, 2008). In the case of MIMs, social aspects are usually incorporated (Wang et al., 2004).

The Unified Theory of Acceptance and Use of Technology (UTAUT), which originates from TAM, predicts the intention of use based on performance expectancy, effort expectancy and social influence, with similar definitions to PU, PEOU and SN respectively, as well as facilitating conditions (Venkatesh et al., 2003), A later extension, known as UTAUT2, incorporated three new factors: hedonic motivation (very similar to PE from TAM3, it is a measure of the extent to which a certain activity is fun or entertaining), price value (or cost associated to an activity) and habit (Venkatesh et al., 2012).

Another major theoretical current to identify the reasons why users select and use certain mass media is the well-known Uses and Gratifications Theory (UGT). It is applied to traditional media as well as to social media, and in subsequent studies it has considered various dimensions of needs and gratifications that individuals voluntarily fulfill with different media. Among the gratifications the previous literature has identified, four stand out: hedonic gratification (all benefits related to leisure, relaxation, fantasy or fun. Vid. Xu et al., 2012); utilitarian gratification (all cognitive and task-oriented profits related to the use of a certain media as immediate access or information sharing. Vid. Kim et al., 2014); social gratification (advantages associated to social ties as social presence or social interaction. Vid. Smock et al., 2011); and technology gratification (satisfactions derived from media appeal or ease of use. Vid. Liu et al., 2016). 
In the field of MIMs, hedonic gratification has been represented by the attribute PE, utilitarian gratification has been measured by PU, and technology gratification has been examined by PEOU (Gan and Li, 2018).

The theoretical framework known as Motivational Model (MM) suggests there are intrinsic motivations for the execution of activities related to information technology usage, as well as extrinsic motivations (Davis et al., 1992). According to this theory, the main intrinsic motivations that promote technology usage are PE and PEOU, while the primary extrinsic motivation is PU (Teo et al., 1999).

In summary, all the abovementioned models (TAM, UTAUT, UGT and MM) share, either in their beginnings or in subsequent extensions or expansions, three attributes that justify the continued use of technological applications from a cognitive standpoint, impacting the user's perceptions: PE (perceived degree to which a certain activity or tool is fun or entertaining), PEOU (perceived level to which the system use is free of effort), and PU (perceived extent to which the application or activity will be useful).

Previous studies have found PE to be a relevant factor in the adoption and use of MIMs (Li et al., 2005), PU to have an impact on the positive regard of the use of instant messaging applications (Huang and Leung, 2009) and PEOU to have a favorable effect on MIM usage (Rouibah, 2008). In consequence, since their relevance in our field of study has been proven, we will include these attributes when evaluating, from a cognitive approach, the level of long-term engagement of WhatsApp users.

Regarding the cognitive indicators used to analyze engaging experiences, the Flow Theory (FT) should be pointed out as one of the models used to analyze long-term engagement in MIMs (Lu et al., 2009; Zhou and Lu, 2011). However, FT is of particular relevance in the analysis of engaging interactions, due to the central concept of flow, conceived as a mental state of involvement in an activity that leads the user to wish to repeat the experience often. Being the person's attention completely absorbed by the activity, the sense of time is altered and a deep involvement removes from awareness the worries and frustrations of the individual. To these components of concentration of attention and unawareness of time, others are added which are not frequently used simultaneously (Csikszentmihalyi and LeFevre, 1989; Csikszentmihalyi, 1990; Koufaris, 2002; Guo and Poole, 2009).

The concept of immersion and the concept of presence (Witmer and Singer, 1998) are initially associated to the field of game and virtual reality technologies. Immersion is used to allude to an engaging experience that causes lack of awareness of surroundings, distortion of 
time and attention focused only on the game (Jennett et al., 2008). The concept of presence is defined as a psychological sense of being in a virtual environment and not in a physical location (Slater et al., 1994), and hence more linked to special gaming experiences.

Except for presence, an immersive activity has many similarities with a flow experience, to the point that immersion and flow have been considered different intensity stages of involvement in an activity or task. The last stages in the scale would be immersion state and flow state, the last one corresponding to the highest level of engagement an individual can reach (Brown and Cairns, 2004; Jennett et al., 2008).

Cognitive absorption (CA), initially developed to explain user behaviors and reactions to information technology, is another conceptual construct of a psychological nature related to FT, immersion and cognitive engagement (Agarwal et al., 1997). The state of cognitive absorption is defined as a state of deep involvement with software, associated with temporal dissociation, focused attention, heightened enjoyment, control and cognitive curiosity (Agarwal and Karahanna, 2000). The level of cognitive absorption reached by the user influences the perceived ease of use and the perceived usefulness of the information system, thus linking to an attitude towards information technology that motivates its use with time or long-term engagement.

The User Engagement Scale (UES) combines the cognitive, affective and behavioral perspectives in the analysis of engagement (O'Brien, 2016). This model conceives engagement as a process with several steps: point of engagement, period of sustained engagement, disengagement, and reengagement (O'Brien and Toms, 2008). When analyzing social media in general, and an instant messaging application in particular, all these steps describe only one experience with the application, as well. SNSs and MIMs allow to chat while doing multiple other tasks at the same time (Birnholtz, 2010), which leads to fragmented WhatsApp conversations in which each participant's interventions take place in between periods of silence. Consequently, a unique experience extends for a certain period of time, in which the system is checked successively. In the case of WhatsApp, therefore, we will consider a session or unique experience as the whole fragmented conversation, i.e., the varying time span during which the user is paying attention to a group or private chat regarding a specific issue. The session covers from the moment that specific issue arises (because someone in the group or the user present it to the group) until the moment the user considers the initial issue that causes the user to be paying attention finalized. During the session or unique experience the user checks WhatsApp and stops using it several times, pending the resolution of the issue at all times. 
UES developed a questionnaire that initially identified six factors in an engaging experience: focused attention, perceived usability, aesthetic appeal, endurability, novelty, and perceived involvement (O'Brien et al., 2018).

After applying this scale to different fields, such as online shopping (O'Brien, 2010) and Facebook (Banhawi and Mohamad Ali, 2011), it was concluded that the initial six factors should be reduced to four: focused attention, perceived usability, aesthetic appeal, and a fourth one that covers the original factors of endurability, novelty and perceived involvement. It has also been proven that only subscales suited to the distinctive features of the subject of study should be considered (O'Brien, 2017).

In relation to cognitive aspects, the UES focused attention subscale is closely related to immersion, FT and CA (O'Brien and Lebow, 2013), since it includes questions about the level of involvement by losing track of time, blocking the world around the user, and the level of absorption of attention in the experience.

Previous studies have analyzed the level of focused attention users reach when using SNSs (Chan and Ma, 2014), the level of time distortion in SNSs users (Turel et al., 2018) or the level of unawareness of the surroundings (Banhawi and Mohamad Ali, 2011). However, the specific analysis of engagement interactions in MIMs has not received attention. For this reason, the analysis of engaging experiences with WhatsApp will be approached through time dissociation, the awareness of surroundings, and the level of concentration on the conversations, and observe their behavior in this MIM application.

\section{Affective perspective of engagement}

It is known that there is a connection between engagement and the user's emotional responses (Yu, 2014), both in the case of continued use or long-term engagement (Beaudry and Pinsonneault, 2010), and in the case of an engaging experience (Mauri et al., 2011). This has led to the study of the user's feelings and emotions as a complementary component to the cognitive aspect in engagement examination.

The literature differentiates between mood and psychological affect or emotion. On the one hand, mood refers to an affective state that is not linked to any specific experience, but represents a general state. On the other hand, an emotion is an affective reaction to stimuli (Damasio, 2005). Studies mainly approach the link between engagement and emotions or affect. In this case, the affective state is directly related to an experience or technological tool that causes such psychological reaction, allowing us to better understand 
the user's perceptions involved in an activity or the emotion mechanisms that motivate the sustained use of an application (Lopatovska and Arapakis, 2011).

There are two main possibilities for the study of emotion. The first considers every emotion should be described through various dimensions that are shared by all of them. The second, however, believes in the existence of specific emotions, different from each other and separately recognizable. The first perspective tends to limit the categories needed to describe any emotion to two: valence (positive/negative) and arousal (calm/excited) (Scherer, 2001; Russell, 1994; Ekman, 1992). According to the second perspective, the number of emotions considered tends to vary among six basic emotions (happiness, sadness, anger, fear, disgust and surprise, plus a seventh that is neutral) and twenty categories from the Positive and Negative Affect Scale (PANAS), ten positive affects (PAS) and ten negative affects (NAS) (Watson et al., 1988). In other occasions the participants are allowed to express their emotions freely, with the words that best reflect their experience (Scherer, 2005). In turn, while the study of long-term engagement involves measuring the feeling a certain activity or application arouses in the user (Wen-Shan et al., 2019), the analysis of an engaging interaction can entail measuring the differences in emotion and intensity before and after the activity (Gwizdka and Lopatovska, 2009; Arapakis et al., 2014).

In this study, and in relation to the analysis of long-term engagement, we include an open question in the questionnaire about the feeling the use of WhatsApp arouses in the user. Regarding the analysis of engaging interaction, the participants are asked about their affective state before and after the WhatsApp session, measuring the difference in feeling throughout the engaging experience.

\section{Behavioral perspective of engagement}

The behavioral perspective includes all actions carried out by the user that reflect continued use (long-term engagement), or involvement throughout the experiences of using an application or during the execution of an activity (engaging interaction). There is a distinction in the user's possible actions considered in the literature. On the one hand, there are those executed immediate and unconsciously (neurophysiological actions), such as brain activity (Lopatovska, 2014). On the other hand, in a second group we find the remaining actions, that is, those that despite possibly having an unconscious component sometimes, other times involve the user's conscious participation, for instance, facial expression (Lopatovska and Arapakis, 2011). It is important to also keep in mind that some of these 
actions have been used at times as indicators for emotional or cognitive aspects of engagement (Lalmas et al., 2014), not just as examples of the behavioral factor of engagement.

In the field of social media, the behavioral perspective addresses the user's behaviors that reflect engaging experiences or stimulate them to use these applications again. There are mainly three different types of actions carried out by the user that allow to measure the level of engagement with social media: the presentation of self, action and participation, and usage and activity counts, i.e., numerical data related to use at individual or network level (McCayPeet and Quan-Haase, 2016).

Regarding the behavioral aspect, we will use parameters related to usage and activity to measure engagement (Lehman et al., 2012). We will analyze the reported usage of the application (minutes per day) in long-term engagement (Kaye and Quinn, 2020), and the frequency of use of WhatsApp during the session in engaging interaction, an indicator that has already been used in human-computer studies (O'Brien et al., 2018).

\section{Research Questions}

The reviewed literature did not provide sufficient support to develop hypotheses about engagement with WhatsApp in Madrid (Spain). We therefore designed an exploratory study by focusing on the following research questions:

RQ1. Do some of the most used cognitive, affective and behavioral aspects in their evaluation justify the long-term engagement of users from Madrid with WhatsApp in an everyday life context?

RQ2. Do some of the most used cognitive, affective and behavioral aspects in their evaluation justify the engaging interaction of users from Madrid with WhatsApp in an everyday life context?

\section{Method}

We followed a qualitative method for the study of long-term engagement and engaging interaction with WhatsApp in everyday life of citizens of Madrid (Spain) with a wide age range by means of semi-structured interviews and questionnaires to measure all long-term engagement and engaging interaction factors. The questionnaires allowed to collect data about the extent to which the participants experience or perceive the factors 
related to engagement addressed in the study and their features, also allowing the comparison to the quantitative results obtained in previous studies. The interviews allowed to clarify the factors to the participants and to discuss the answers previously selected by them in the questionnaires. Moreover, during the interviews we could explain to the participants which kind of experience they had to recount, facilitating the collection of in-depth descriptions a complex phenomenon such as engagement (Harris and Brown, 2010). The items of the questionnaires and interview are shown in Appendix.

This study considers the participation of broader segments of the population, including minors and adults over the age of fifty, with the purpose of collecting a wide range of possibilities of behavior in factors related to the cognitive, affective and behavioral aspects of engagement. These age subsets are harder to reach out to and often require a high degree of trust to initiate the contact. In addition, in the case of minors, previous contact with a trusted person greatly facilitates obtaining consent from their legal guardians for their participation. Finally the snowball sampling was selected, since it is a useful methodology in exploratory qualitative research, especially when it involves subsets of the population for which a high degree of trust is required (Baltar and Brunet, 2012). On the other hand, social media offers the possibility to easily construct snowball samples (Atkinson and Flint, 2001). Since WhatsApp is the object of analysis, despite the limitations of this method, such as the possibility of a lack of representativeness in the sample regarding population characteristics, snowball sampling was considered to be the most appropriate recruitment strategy for this research.

The occurrence of some sort of bias in the sample can be partially countered by increasing its size (Van Meter, 1990). In similar studies the samples usually range from 17 people, when solely conducting interviews (O'Brien and Toms, 2008), to 40 people, when various experiments are added to the questionnaires (Jennett et al., 2008). Therefore, in our case, even though we only carried out interviews and questionnaires, a sample of 30 people has been selected, 14 men and 16 women from 13 to 58 years old.

The procedure started with the constitution of the sample. For that, we asked a teacher from a Secondary Education Institute in Madrid, in her fifties, who is an active user of WhatsApp, to choose all the WhatsApp group chats - both in a professional and private context-in which she participated daily, excluding the group chats she only consulted or participated in sporadically. This initial individual was chosen because in her usual group 
chats there were people from a wide range of ages and with different professional, family and friendship ties. In a first wave, she helped to establish contact with over 45 people with whom she had a high level of trust, among whom she distributed a document including the purpose of the research, indicating that the questionnaires and the interviews would be carried out at the Institute, the approximate duration in school hours, the general content of the data collection tools, as well as the request for written consent for the audio recording of the interviews with the commitment to respect the anonymity and privacy of the participants, only publishing small fragments of the transcript of the audio files to illustrate some relevant aspects. In the case of minors, a second document of consent of their legal guardians for the participation of the minor during school hours in the Institute was added. Among them, 30 people agreed to take part in the study for free, with the consent of their legal guardians in the case of minors, a number considered sufficiently representative in regards to factors such as age, gender and type of relationship with the initial individual, so it was not necessary to proceed to a second wave to collect additional participants. The sample distribution is as follows:

a. Family unit group chat (parents and children): 3 participants.

b. Broader family group chat (siblings, their husbands, spouses and children): 5 participants.

c. Group chat of friends from adolescence: 3 participants.

d. Group chat of current friends: 7 participants.

e. Class group chat professor-students for a project: 9 participants.

f. Professor group chat for professional affairs: 3 participants.

Table I summarizes the demographic data of the participants.

Table I. Participants' demographics 
All the interviews and questionnaires were carried out in Spanish at the Institute where the initial individual worked, during school hours. The translation to English was carried out by one of the authors and revised by a professional translator. The participants first completed the questionnaire on long-term engagement. After completing the questionnaire, a brief interview with the participants allowed for a deeper understanding of the scope and meaning of the answers. Afterwards, the participants were asked to choose and briefly describe a specific and usual experience in their daily life in which they were paying attention to a WhatsApp conversation, in relation to which they completed the questionnaire about engaging interaction, asking for the parameter values before and after the event. Likewise, after answering the questionnaire, a brief interview was held with the participants to clarify the meaning of their responses. The interview and questionnaires took approximately 30 minutes. The collection of data was carried out between the months of April and May of 2018.

The audio recordings of the interviews were transcribed and entered in NVivo to simplify their study. Content analysis was employed for the analysis of the interviews and questionnaires. Its application to the interviews allowed to infer which are the most frequent situations and the most relevant ones from an affective or emotional perspective that drive the users to pay attention to a WhatsApp group chat in an everyday life context, as well as allowed to delve deeper in the description of engaging interactions. Content analysis was also employed for the analysis of the questionnaires, allowing to look into the features and intensity levels with which the participants experience the engagement aspects addressed in the study. In addition, since ordinal scales using 3, 5 and 7 ranks are popular in content analysis (Krippendorff, 2013), the numerical equivalent in a 5-point scale allowed to compare the results obtained here with other quantitative ones obtained in previous studies on engagement.

\section{Results}

During the interviews, the participants were asked to indicate which issues were the most frequent and which were the most relevant emotionally or affectively considering conversations in their daily life they were especially paying attention to until they were resolved. Then they were asked to briefly describe an experience of these characteristics. Interviewees indicated that the situations that most frequently involved engaging 
conversations were those related to their primary occupation, followed by those related to the family unit, friends and social relationships. On the other hand, issues concerning their significant others, their family unit and their friends are the most important affectively or emotionally.

Content analysis of the engaging experiences described by the participants shows that the exchange of information or data clearly prevails in the conversations chosen by the interviewees regardless of the setting, be it family, personal or professional. In relation to the family sphere, S14 (man, 44 years old) comments: "For example with my son. On weekends he hangs out [with friends...]. But these [friends] are older, my son is 17 years old, and he wants to get together with them. He says: 'I'm going to have a pizza with them ', I say: 'Ok, by then you come home soon '. [...] You use WhatsApp: 'Where are you, Ricky? ' [...] He says: 'Now, now, we are leaving now, we are leaving now ', Then you are pending: 'Ricky, where are you? [...] And so on until, at the end, he appears through the door". In relation to the personal sphere, these experiences are representative: "When the time we have to join friends comes, I am paying attention to see if there is any change or if I must bring a bottle of red or white wine" (S6, man, 47 years old); "Just yesterday I was going to meet a group of friends and I asked: Where do we meet? At what time?" (S15, woman, 14 years old). Regarding daily information related to work, S12 (woman, 53 years old) relates: "Some [messages] are important to my work, for example, a colleague who tells me that he or she is not going to go the next day. Automatically I have to write to my team and tell them, if they are going to arrive earlier, to find a substitute $[\ldots]$ In the meantime, you receive another [message] from another colleague who is in a jam and who is not going to arrive on time and must be replaced".

Much less frequent are conversations about establishing romantic relationships and finally conversations related to social relationships. In relation to the first, this fragment is illustrative: "You are talking to a girl you are very interested in, and you decide to take a big step, because you have never had a date with her. You've been talking to her for a long time and you want to go out with her for coffee [...] But, after all, it is important for you considering that there is a feeling behind. So you ask in a more or less elegant way: 'How about we meet for coffee this weekend?' It's nonsense, but if you really believe that there is something important behind it, you are waiting and it may take a long time or it may take a very short time, but I assure you that [...] I will be aware of the phone" (S13, man, 23 years old). Regarding social relationships, S30 (woman, 56 years old) comments: "Now I remember [a conversation] I was paying a lot of attention to one whole Friday afternoon. 
Two acquaintances $[\ldots]$ had a dispute and I was there in the middle. An unpleasant situation, of immaturity, because people on WhatsApp seem to have more freedom to speak, people are more uninhibited. I was there in the middle, trying to appease, acting as mediator, answering one and the other over and over".

In summary, the sample analyzed highlights the essentially informative nature of the messages exchanged through WhatsApp, commonly used to resolve issues related to daily life.

\section{Long-term engagement}

The measuring of long-term engagement was analyzed by three factors from a cognitive perspective: PE, PU, and PEOU. The results are summarized in Table II.

\section{Table II. Long-term engagement from a cognitive perspective}

Regarding PE, half of the participants considered WhatsApp to be 'considerably fun', but twelve others selected 'moderately fun'. In relation to PU, a majority of participants selected 'considerably useful' or 'very useful'. Finally, in PEOU almost all participants considered the application 'very easy' or 'considerably easy' to use. In summary, WhatsApp users think it is quite fun, it is very useful and it is very easy to use.

In the interviews, users point out that the fun aspect of WhatsApp emerges in any group chat sometimes, being more often in friend group chats, but it is not one of the factors that drive to its use, contrary to the case of utility. In relation to that, S7 (woman, 51 years old) comments: "There are friend group chats dedicated to funny things, while in family group chats you combine both [...] Fun doesn't influence me in any way, nor makes me pay attention, I don't care [...] I don't waste my time with that [funny videos]".

WhatsApp is essentially perceived as a useful tool for the management and solving of daily tasks, regardless of the user's age or occupation. S26 (man, 58 years old) says in regards to that: "I have a lot of contact with people [...] and through WhatsApp they inform me of what's going on back in town [...] You go to the countryside and you are informed about so many things". S9 (woman, 52 years old) summarizes this characteristic very well: "Whatever is in WhatsApp is useful for me in a daily life kind of way. Whatever isn't on WhatsApp doesn't exist". 
In relation to the perceived ease of use, the participants highlight that this factor boosts its use by older people, facilitating communication with parents. S7 (woman, 51 years old), for instance, comments in regards to this: "[WhatsApp] is very user-friendly, since an 87-year-old person like my father can use it like you and I do, and we use it the same way they do". This characteristic, however, causes inconveniences, among which the main ones are misunderstandings and addiction because of excessive use. S5 (woman, 13 years old) points out that WhatsApp is "pretty [easy to use], but sometimes (depending on the person) they interpret it one way or another". In regards to addiction, S30 (woman, 56 years old) claims: "[WhatsApp] causes a little bit of addiction, because you're kind of like hooked, to see what's going on, constantly looking, because you think since everyone is going to communicate through it, you pay attention to see if something happens. It's a very controlling attachment in a way".

Regarding the affective perspective, the positive feelings mentioned the most by the users have been fun (more than half of participants consider WhatsApp is usually, frequently or always amusing), then joy (half of participants consider it makes them sometimes, usually or frequently happy), and peace (less than half of participants think it sometimes or usually gives them tranquility). The negative emotions mentioned the most by the users have been anger (half of participants think WhatsApp sometimes annoys them), then burden (one third of participants consider that the application sometimes harasses them), boredom (one third of them consider that WhatsApp sometimes bores them), and stress (some of them think it sometimes stresses them). In summary, positive emotions are more frequent than negative emotions.

The results in our sample seem to reflect a tendency in WhatsApp users to combine feelings among three pairs of opposing feelings, being a positive emotion and the corresponding negative one the two extremes of these pairs: fun/boredom, peace/stress, and joy/anger. The participants think WhatsApp is frequently amusing, but having to go through the same process of checking for texts and replying to them many times a day, with no news or significant variation in the topic or the participants of the conversation, sometimes causes boredom in the users. On the other hand, WhatsApp usually gives them tranquility, a feeling justified by the informational use the participants of our sample give to the application. This real-time flow of information reassures the users that the everyday activities and tasks will be carried or sorted out successfully. However, at times, the convergence of multiple aspects of everyday life in short periods of time can cause stress. Lastly WhatsApp usually makes the interviewees happy, but they admit that some WhatsApp group chats of a circumstantial or 
work-related nature (for instance, group chats with other parents from the kids' school or group chats with coworkers) can occasionally bombard the user with texts deemed irrelevant or unnecessary, as well as repetitive, which annoys them, and causes them anger and to feel burdened.

Lastly, from the behavioral perspective, the majority of interviewees use WhatsApp between 5 and 10 times a day, usually 6 minutes each time they use the application. We can therefore summarize by saying users usually dedicate between 30 minutes and 1 hour to WhatsApp throughout the day.

\section{Engaging interaction}

The cognitive factors analyzed in relation to engaging interaction have to do with attention: losing track of time, unawareness of the world around, and absorption of attention. The results are summarized in Table III.

Table III. Engaging interaction from a cognitive perspective

In relation to time awareness during the engaging interactions, half of participants were 'highly aware' or 'considerably aware' of the passing of time during sessions, but thirteen others selected 'moderately aware' or 'slightly aware'. Regarding awareness of surroundings during the engaging experiences, half of participants were 'highly aware' or 'considerably aware' of the world around them, but other ten selected 'slightly' aware of the surroundings. Finally, in relation to the degree of concentration during the sessions in the sample, most of the participants were 'slightly paying attention' or 'barely paying attention' to the conversation the times they checked WhatsApp. If we consider them globally, the results reflect a moderate to low degree of engagement during the experiences with WhatsApp from a cognitive perspective.

In the interviews, the participants point out the influence the importance of the conversation has on the three factors. Since the conversations are usually trivial, about 
aspects of daily life, the level of attention is low and the level of awareness is moderate or high. S13 (man, 23 years old) expresses it this way: "When something's important and suddenly you have to reply, it's true that you are not very aware of what happens around you, because you focus".

In turn, the three factors are mutually linked in the interviewees' opinion, in such a way that a change in any of them prompts a variation in the intensity level of the others. In this regard, S8 and S26 say this about the relation between low and high levels of concentration and the subsequent variation in the awareness of surroundings: "I'm not so concentrated that I don't realize if someone comes in or gets out" (S8, man, 53 years old); "Yeah, I wasn't very aware of what happened around me. You cut down your reality in that moment and you focus, of course" (S26, man 58 years old).

In the same way, participants concur that the low levels of these factors make multitasking possible, that is, the simultaneous execution of multiple daily tasks, with maintaining conversations on WhatsApp being one of them. In relation to that, S4 (woman, 46 years old) comments: "No [I'm focused], I can be doing that [having a conversation on WhatsApp] and something else, watching TV, or spending time with the girls. I can absolutely be doing something else".

Regarding the affective perspective, the most frequent feeling at the beginning of the engaging experience is neutrality (mentioned by half of interviewees), followed by joy and stress. In turn, the most frequent feelings at the end of the sessions are satisfaction (mentioned by a third of participants), followed by joy, relief, displeasure, and disappointment.

If we make the comparison between the initial and final emotions mentioned by the participants, in those cases in which the users describe themselves as neutral at the beginning of the experiences, the frequency of positive final feelings double the number of users with negative final feelings. In summary, the sessions during which they are paying attention to an issue in WhatsApp evoke more final positive feelings, although negative final emotions are also possible.

The interviewees have also expressed these final feelings are closely related to the result of the issue that started the conversation of the session. If the issue is settled successfully, the feeling is positive, however, if the result is not satisfactory, negative 
feelings are aroused. This aspect reinforces the idea of WhatsApp as a useful application in everyday life for the resolution of daily affairs in the user's closest sphere, which is usually favorable.

Lastly, in relation to the behavioral component, during the experiences the interviewees checked WhatsApp mostly between 10 and 15 times, with a usual duration for the sessions that ranges between 5 and 10 hours. In summary, the sessions during which the participants were paying attention to an issue in WhatsApp usually did not last longer than a day.

\section{Discussion}

\section{Long-term engagement}

In relation to the cognitive point of view of long-term engagement, the questionnaire included questions about three factors: PE, PU, and PEOU. In a study on engagement in social media the results regarding PE indicated that the users considered social media moderately fun (Hussein and Hassan, 2017). MIM applications are generally perceived as quite fun in China (Wang et al., 2012) and in Korea (Yoon et al., 2015). When discussing specific MIM applications, LINE was considered moderately fun (Dhir et al., 2018), WeChat was rated by the users as moderately to quite fun (Zong et al., 2019), and WhatsApp, in a previous study, was perceived as quite fun (Fernández Robin et al., 2017). According to our sample, WhatsApp is moderate to high fun, so the results obtained match the ones from previous studies. Just as an observation, they align more with the results obtained for LINE and WeChat than with the previous results for WhatsApp itself, possibly because of the specific context of daily life in this study. Additionally, it has been concluded that PE is decisive in the adoption and the continued intention of use of SNSs (Sullivan and Koh, 2019) as well as MIMs(Jiang and Deng, 2011; Wang et al., 2012a). Again, the results obtained in our sample match the ones obtained for LINE, in that to WhatsApp users in Madrid PE is not the reason for the use of this application, but a characteristic that emerges additionally.

The relevance of PU in the continued intention of use of social media has not always been proven (Sullivan and Koh, 2019). However, there seems to be an agreement when it comes to the positive influence of PU on the adoption and continued use of MIMs (Yoon et al., 2015; Zhou et al., 2015; Wang et al., 2012a). MIMs in China have been generally 
considered quite useful (Wang et al., 2012). Despite the fact that LINE is once again the application with the lowest level regarding this attribute (Dhir et al., 2018), in a previous study WhatsApp obtained again a very high rating in functioning expectation (Fernández Robin et al., 2017), with our sample supporting the perception of WhatsApp as a very useful tool used in the management and solving of simple daily life tasks in both the professional and private fields.

Previous studies have come to the conclusion that PEOU has a positive influence on the intention of use of MIMs (Jiang and Deng, 2011). The results obtained in the sample from Madrid confirm the very high rating of MIMs regarding this attribute in the literature, WhatsApp included (Yoon et al., 2015; Dhir et al., 2018; Fernández Robin et al., 2017), with it being a key factor in the adoption of this application by older people.

In summary, WhatsApp obtains very high values in the attributes corresponding to the cognitive point of view of long-term engagement, more even than other SNSs and MIMs applications, so these factors are sufficient to justify the long-term engagement in an everyday life context in Madrid.

Regarding the affective perspective, the results obtained in our sample are consistent with the ones obtained previously in relation to SNSs and MIMs. Among the positive emotions in relation to MIMs, joy stands out (Zaman et al., 2010), and among negative emotions in MIMs the literature has highlighted annoyance (Nguyen and Fussell, 2016) and stress (Fondevila-Gascón et al., 2019).

The behavioral perspective of long-term engagement has been measured by the reported usage of WhatsApp. The data on daily use of SNSs depends on the user's age, among other factors, but it usually fluctuates between 1 hour/day and 3 hours/day (Wen-Shan et al., 2019; Korhan and Ersoy, 2016; Kim et al.,2011). The frequency of daily use of MIMs tends to be lower than for SNSs. The average of use fluctuates between 30 minutes/day and 2 hours/day for WeChat (Zong et al., 2019; Lien and Cao, 2014), and it is around 55 minutes/day for WhatsApp (Kaye and Quinn, 2020; Elareshi and Ziani, 2019). LINE is once again the exception due to its low level of use, since $40 \%$ of its users use this application for a maximum of 30 minutes/day (Chou and Liu, 2016). The participants of our sample usually dedicate between 30 minutes/day and 1 hour/day to the application, confirming the most frequent previous results on use of WhatsApp or WeChat. In consequence, from the behavioral perspective, the daily usage is a sufficient attribute to justify the continued use of WhatsApp. 
In summary, all factors analyzed regarding the three perspectives considered present compatible values with a high level of long-term engagement for WhatsApp users in Madrid in an everyday life context, justifying the selection of said attributes as valid indicators to evaluate the level of long-term engagement reached by the application users.

\section{Engaging interaction}

Engaging interaction has been also analyzed from the cognitive, affective, and behavioral perspectives. Regarding the cognitive point of view, participants were asked about attention during WhatsApp sessions, operationalized through awareness of time, awareness of surroundings and concentration on the conversation.

In the literature there is no unanimous stance on the influence attention has on engagement. In the field of MIMs, while some studies conclude that the attention did not predict the intention of continued use of LINE (Dhir et al., 2018), other studies confirm attention is directly or indirectly related to the intention of adoption and continued use of MIMs (Lu et al., 2009; Zhou and Lu, 2011).

The three dimensions of attention (time, surroundings and concentration) are usually analyzed globally, obtaining results that fluctuate between low (O'Brien and Toms, 2010; McCay-Peet et al., 2012) and medium values (O'Brien, 2010; O'Brien and Toms, 2013) in online shopping and searching tasks. In relation to MIMs, medium attention values were obtained for MIM applications (Lu et al., 2009) and for LINE (Dhir et al., 2018). In our case, we obtained medium to low values of attention if we consider all three factors globally.

The global moderate to low level of engagement during the sessions from a cognitive perspective in WhatsApp would have reached a slightly higher level if it had not been for the negative influence of concentration. A possible explanation for this is that throughout the sessions the participants did not focus the attention on that conversation only, and they mostly focused simultaneously on other everyday tasks unrelated to the application or even to the texts exchanged in other WhatsApp group chats. In summary, the multitasking that defines WhatsApp usage among the participants negatively affects the cognitive processes of users throughout the use of this application, increasing awareness of time and surroundings, and decreasing concentration. This fact remains consistent with the results obtained in previous studies on text-based conversations, including MIMs (Nguyen and Fussell, 2016).

The affective point of view related to engaging experiences has been operationalized by observing the difference in feelings throughout the sessions, since people engaged in a 
conversation experience mostly positive sentiments, whereas people that are less involved have mostly negative feelings (Cegala, 1989), as in the case of multitasking (Guerrero and Burgoon, 1996). Regarding MIMs, the most predominant positive feeling aroused in engaging experiences is enjoyment, while the most significant negative feelings associated to less engaging experiences are frustration and annoyance (Nguyen and Fussell, 2016). Our results confirm these previous results. The positive feelings at the end of the sessions that are more frequently mentioned by interviewees are satisfaction and joy (similar to enjoyment), while negative feelings present at the end of the sessions are displeasure (comparable to annoyance) and disappointment (comparable to frustration). On the other hand, the frequency of positive final feelings is greater than negative final feelings after the experiences when the user is neutral at the beginning. In consequence, the predominance of positive feelings that the experiences with WhatsApp suggest is a favorable indicator to the existence of engaging interactions in the participants of this study.

The behavioral perspective of engaging interaction has not been observed previously, since usage indicators for MIMs in previous studies are limited to global data of the use of the application. Considering users spend the same amount of time each time they check WhatsApp, in general and during the session, that is, 6 minutes, we will obtain that the users spend between 60 minutes and 90 minutes in WhatsApp during the interactions. This period of time implies between $100 \%$ and $150 \%$ more of dedication to WhatsApp than usual, which clearly leads to considering WhatsApp sessions as engaging experiences.

In summary, the three cognitive, affective, and behavioral factors considered in this study present values that are compatible with the conception of WhatsApp sessions as engaging activities, although the three attributes corresponding to attention present difficulties adapting to engagement analysis for text messaging applications. The usual measurings associated with attention display low values compared to other attributes used in the analysis of long-term engagement, even though we are limiting the sessions to cases in which the user is interested in the issue and they are paying attention to a conversation. Other cognitive factors traditionally considered, such as novelty or aesthetic appearance, are less useful in the case of text messaging.

We can conclude that it is necessary to use other cognitive attributes better suited for the specifically informative characteristics of this kind of applications. For example, the cognitive concepts widely used in the information retrieval field, such as interest or urgency in solving the information need, based on the uncertainty principle (Kuhlthau, 2004), would be 
perfectly adapted to the engaging experiences reported by the participants, and would justify the high level of involvement confessed by interviewees.

The engagement model developed by O'Brien and Toms has proved helpful in the analysis of engaging interactions (O'Brien and Toms, 2008). In this way, the continued use of any MIM would consist of an indefinite and cyclical succession of individual and even simultaneous experiences if the user is participating in several conversations at the same time. According to this scheme, an engaging interaction or session is a process in which we can distinguish three stages: a point of engagement (the beginning of the session caused by an element that grabs the attention of the user), subsequent periods of engagement (checking WhatsApp) and disengagement (doing other activities), and a final stage of non-engagement (the issue is considered finalized).

Incorporating this model to the analysis of long-term engagement and engaging interactions enables the adoption of other engagement measurings previously used in the information retrieval area, such as Absence Time or Session Duration, for the description of aspects related to behavioral perspective. Indeed, Absence Time or Session Duration could be considered measurings based on the time the user takes for each of the already mentioned stages (Lalmas et al., 2014). Adapting these measurings to WhatsApp's characteristics, we suggest the measuring Frequency of Use (based on Absence Time) to measure long-term engagement from a behavioral point of view, defined as the average of time in minutes that WhatsApp is checked during the day or in a 24-hour period. In the sample used here the Frequency of Use ranges between 30 and 60 minutes a day, as we have mentioned previously. To measure engaging interaction from the behavioral perspective, we suggest the Consultation Index, defined as the average of the number of times WhatsApp is checked during each hour of the session. In the sample for this study, the Consultation Index ranges between 1 and 3 (between 1 and 3 times per hour of the session).

\section{Conclusion}

The analysis carried out has allowed to make some characteristics of WhatsApp related to the engagement known, highlighting the relevance of factors such as PU over others like PE in an everyday life context, the influence of PEOU in the adoption and continued use of WhatsApp by older users, or how the intensity level in various factors 
depends on the importance the issue or conversation that causes the engaging experience has for the user.

The attributes used in this study to evaluate long-term engagement and engaging interactions with WhatsApp in an everyday life context in Madrid have been proven relevant, except for factors related to attention, indicating that users reach a low level of flow state during sessions. A possible explanation for this is the marked multitasking character that defines WhatsApp among the participants in our sample, decreasing the intensity of the factors that have an impact on attention. We have presented alternatives to solve this peculiar circumstance in MIMs, based on the uncertainty principle from the information retrieval field, given the informational utility of WhatsApp and the peculiar characteristics compared to other social media platforms.

The study is limited to Madrid and WhatsApp, and should be expanded to other cities and other informative tools used by people simultaneously with WhatsApp. It would also be necessary to include people over 60 years old, adding other attributes belonging at least to a social perspective.

\section{Appendix \\ Questionnaire on long-term engagement}

1. Demographic aspects

2. Frequency of use of WhatsApp

3. To what extent is using WhatsApp fun?

Not fun at all(1) Slightly fun(2) Moderately fun(3) Considerably fun(4) A lot of fun(5)

4. To what extent is using WhatsApp useful?

Not useful at all(1) Slightly useful(2) Moderately useful(3) Considerably useful(4) Very useful(5)

5. To what extent is it easy to use WhatsApp, can I do what I want?

Not easy at all(1) Slightly easy(2) Moderately easy(3) Considerably easy(4) Very easy(5) 
6. Do you experience any positive feelings while using WhatsApp? Specify the frequency of each of them

Never(1) Sometimes(2) Usually(3) Frequently(4) Always(5)

7. Do you experience any negative feelings while using WhatsApp? Specify the frequency of each of them

8. Never(1) Sometimes(2) Usually(3) Frequently(4) Always(5)

9. How many times on average do you usually use WhatsApp, without including vacations or weekends?

10. How long are you usually connected on average each of those times?

Questionnaire on engaging interaction

1. Considering the times you checked WhatsApp during the experience you have described, how aware were you of what happened in your surroundings?

Not aware at all(1) Slightly aware(2) Moderately aware(3) Considerably aware(4) Highly aware(5)

2. Considering the times you checked WhatsApp during the experience you have described, how aware were you of the time that passed?

Not aware at all(1) Slightly aware(2) Moderately aware(3) Considerably aware(4) Highly aware(5)

3. Considering the times you checked WhatsApp during the experience you have described, how much attention were you paying to the conversation?

Barely paying attention(1) Slightly paying attention(2) Moderately paying attention(3) Considerably paying attention(4) Completely paying attention(5)

4. From an emotional perspective, were you neutral or did you experience any positive or negative feelings before the beginning of the experience?

5. From an emotional perspective, were you neutral or did you experience any positive or negative feelings right after finalizing the experience?

6. How long did the experience last from the beginning until considering the issue finalized?

7. How many times did you check WhatsApp from the beginning until considering the issue finalized?

Script for the semi-structured interview 
1. Most frequent situations that drive you to pay attention to a WhatsApp group chat.

2. Most relevant situations from an affective or emotional perspective that drive you to pay attention to a WhatsApp group chat.

3. Description of an experience in your daily life in which you were paying attention to a WhatsApp conversation.

4. In regards to the two questionnaires on long-term engagement and engaging interaction, briefly explain why you chose those options.

\section{References}

Agarwal, R., Sambamurthy, V. and Stair, R. (1997), 'Cognitive Absorption and the adoption of new information technologies', Academy of Management Annual Meeting Proceedings, Vol. 1997 No. 1, pp. 293-297.

https://doi.org/10.5465/ambpp.1997.4983719

Agarwal, R. and Karahanna, E. (2000), 'Time flies when you're having fun: cognitive absorption and beliefs about information technology usage', MIS Quarterly, Vol. 24 No. 4, pp. 665-694.

http://dx.doi.org/10.2307/3250951

Ajzen, I. (1991), 'The theory of planned behaviour', Organizational Behaviour and Human Decision Processes, Vol. 50 No. 2, pp. 179-211.

https://doi.org/10.1016/0749-5978(91)90020-T

Arapakis, I., Bai, X. and Cambazoglu, B.B. (2014), 'Impact of response latency on user behavior in web search', in Geva, S. and Trotman, A. (Ed.s), SIGIR '14:Proceedings of the 37th International ACM SIGIR Conference on Research \& Development in Information Retrieval, ACM, New York, pp. 103112.

https://doi.org/10.1145/2600428.2609627

Arapakis, I., Lalmas, M. and Valkanas, G. (2014a), 'Understanding within-content engagement through pattern analysis of mouse gestures', in Li, J. and Wang, X.S. (Ed.s), CIKM '14: Proceedings of the 23rd International Conference on Information and Knowledge Management, ACM, New York, pp. 14391448. 
http://dx.doi.org/10.1145/2661829.2661909

Arapakis, I., Lalmas, M., Cambazoglu, B., Marcos, M.C. and Jose, J.M. (2014b), 'User engagement in online news: Under the scope of sentiment, interest, affect, and gaze', Journal of the Association for Information Science and Technology, Vol. 65 No. 10, pp. 1988-2005.

http://dx.doi.org/10.1002/asi.23096

Atkinson, R. and Flint, J. (2001), 'Accessing hidden and hard-to-reach populations: Snowball research strategies', Social Research Update, Vol. 33, pp. 1-5.

Attfield, S., Kazai, G., Lalmas, M. and Piwowarski, B. (2011), 'Towards a science of user engagement (Position Paper)', in Carmel, D., Josifovski, V. and Maarek, Y. (Ed.s), WSDM Workshop on User Modelling for Web Applications (WSDM '11), ACM, New York, pp. 1-8.

Baltar, F. and Brunet, I. (2012), 'Social research 2.0: Virtual snowball sampling method using Facebook', Internet Research, Vol.22 No.1, pp. 57-74.

https://doi.org/10.1108/10662241211199960

Banhawi, F. and Mohamad Ali, N. (2011), 'Measuring user engagement attributes in social networking application', in 2011 International Conference on Semantic Technology and Information Retrieval (STAIR 2011), IEEE, Washington, pp. 297-301.

http://dx.doi.org/10.1109/STAIR.2011.5995753

Beaudry, A. and Pinsonneault, A. (2010), 'The other side of acceptance: Studying the direct and indirect effects of emotions on information technology use', MIS Quarterly, Vol. 34 No. 4, pp. 689-710.

http://dx.doi.org/10.2307/25750701

Bennett, J., Butler, K. and Whiteside, J. (1989). 'Usability engineering', tutorial presented at CHI'89, Associaton for Computing Machinery, Austin TX, 1 May.

Birnholtz, J. (2010), 'Adopt, adapt, abandon: Understanding why some young adults start, and then stop, using instant messaging', Computers in Human Behavior, Vol. 26 No. 6, pp. 1427-1433.

https://doi.org/10.1016/j.chb.2010.04.021 
Boyd, D.M. and Ellison, N.B. (2007), 'Social network sites: Definition, history, and scholarship', Journal of Computer Mediated Communication, Vol. 13 No. 1, pp. 210-230.

https://doi.org/10.1111/j.1083-6101.2007.00393.x

Brown, E. and Cairns, P. (2004), 'A grounded investigation of game immersion', in Dykstra-Erickson, E. and Tscheligi, M. (Ed.s), 2004 Conference on Human Factors in Computing Systems (CHI 2004), pp. 1297-1300.

http://dx.doi.org/10.1145/985921.986048

Carroll, J.M. and Thomas, J.M.C. (1988), 'Fun', ACM SIGCHI Bulletin, Vol. 19 No. 3, pp. 21-24.

https://doi.org/10.1145/49108.1045604

Cegala, D.J. (1989), 'A study of selected linguistic components of involvement in interaction', Western Journal of Speech Communication, Vol. 53 No. 3, pp. 311-326.

http://dx.doi.org/10.1080/10570318909374309

Chan, W.W.L. and Ma, W.W.K. (2014), 'The influence of playfulness and subject involvement on focused attention when using social media', Journal of Communication and Education, Vol. 1 No. 1, pp. 16-27.

Chou, M.C. and Liu, C.H. (2016), 'Mobile instant messengers and middle-aged and elderly adults in Taiwan: Uses and Gratifications', International Journal of Human-Computer Interaction, Vol. 32 No. 11, pp. 835-846.

https://doi.org/10.1080/10447318.2016.1201892

Csikszentmihalyi, M. (1990), Flow: The psychology of optimal experience, Harper, New York, NY.

Csikszentmihalyi, M. and LeFevre, J. (1989), 'Optimal experience in work and leisure', Journal of Personality and Social Psychology, Vol. 56 No. 5, pp. 815-822.

http://dx.doi.org/10.1037/0022-3514.56.5.815 
Damasio, A. (2005), Descartes' error: Emotion, reason, and the human brain, Penguin, New York.

Davis, F.D. (1989), 'Perceived usefulness, perceived ease of use, and user acceptance of information technology', MIS Quarterly, vol. 13 No. 3, pp. 319-339.

http://dx.doi.org/10.2307/249008

Davis, F.D., Bagozzi, R.P. and Warshaw, P.R. (1992), 'Extrinsic and intrinsic motivation to use computers in the workplace', Journal of Applied Social Psychology, Vol. 22 No. 14, pp. 1111-1132. https://doi.org/10.1111/j.1559-1816.1992.tb00945.x

Dhir, A., Kaur, P. and Rajala, R. (2018), 'Continued use of mobile instant messaging apps: A new perspective on theories of consumption, flow, and planned behavior', Social Science Computer Review, 22/11/2018.

https://doi.org/10.1177/0894439318806853

Ekman, P. (1992), 'An argument for basic emotions', Cognition and Emotion, Vol. 6 No. 3-4, pp. 169200.

https://doi.org/10.1080/02699939208411068

Elareshi, M. and Ziani, A.K. (2019), 'Digital and interactive social media among middle east women: Empirical TAM study', Media Watch, Vol. 10 No. 2, pp. 235-250.

http://doi.org/10.15655/mw/2019/v10i2/49642

Fantoni, S.F., Stein, R. and Bowman, G. (2012), 'Exploring the relationship between visitor motivation and engagement in online museum audiences', available at: http://www.museumsandtheweb.com/mw2012/papers/exploring_the_relationship_between_visitor_m ot (accessed 12 July 2020).

Fenech, A.M. (2015), 'A study of engagement in active and passive roles in casual leisure occupations', The Open Journal of Occupational Therapy, Vol. 3 No. 2, article 6.

http://dx.doi.org/10.15453/2168-6408.1134 
Fernández Robin, C., McCoy, S. and Yáñez, D. (2017), 'WhatsApp', in Meiselwitz, G. (Ed.), Proceedings of the 9th International Conference on Social Computing and Social Media: Applications and Analytics, SCSM 2017, Springer, Berlin, Part II, pp. 82-90.

Fishbein, M. and Ajzen, I. (1975), Belief, attitude, intention, and behavior: An introduction to theory and research, Addison-Wesley, Reading.

Fondevila-Gascón, J.F., Marqués-Pascual, J., Mir-Bernal, P. and Polo-López, M. (2019), 'Uses of WhatsApp in the Spanish university student. Pros and cons', Revista Latina de Comunicación Social, Vol. 74, pp. 308-324.

http://doi.org/10.4185/RLCS-2019-1332en

Fundación Telefónica (2019), Sociedad Digital en España 2018, Penguin, Barcelona.

Gan, C. and Li, H. (2018), 'Understanding the effects of gratifications on the continuance intention to use WeChat in China: A perspective on uses and gratifications', Computers in Human Behavior, vol. 78, pp. 306-315.

https://doi.org/10.1016/j.chb.2017.10.003

Guerrero, L.K. and Burgoon, J.K. (1996), 'Attachment styles and reactions to nonverbal involvement change in romantic dyads: Patterns of reciprocity and compensation', Human Communication Research, Vol. 22 No. 3, pp. 335-370.

http://doi.org/10.1111/j.1468-2958.1996.tb00371.x

Guo, Y.M. and Poole, M.S. (2009), 'Antecedents of flow in online shopping: A test of alternative models', Information Systems Journal, Vol. 19 No. 4, pp. 369-390.

http://doi.org/10.1111/j.1365-2575.2007.00292.x

Gwizdka, J. and Lopatovska, I. (2009), 'The role of subjective factors in the information search process', Journal of the American Society for Information Science and Technology, Vol. 60 No. 12, pp. 24522464.

https://doi.org/10.1002/asi.21183 
Hamari, J., Shernoff, D.J., Rowe, E., Coller, B., Asbell-Clarke, J. and Edwards, T. (2016), 'Challenging games help students learn: An empirical study on engagement, flow and immersion in game-based learning', Computers in Human Behavior, Vol. 54, pp. 170-179.

http://dx.doi.org/10.1016/j.chb.2015.07.045

Harris, L.R. and Brown, G.T.L. (2010), 'Mixing interview and questionnaire methods: Practical problems in aligning data', Practical Assessment, Research, and Evaluation, Vol. 15, article 1

https://doi.org/10.7275/959j-ky83

Haywood, N. and Cairns, P. (2005), 'Engagement with an interactive museum exhibit', in van der Veer, G. (Ed.), 2005 Conference on Human Factors in Computing Systems (CHI 2005), ACM, New York, pp. 113-129.

http://dx.doi.org/10.1007/1-84628-249-7_8

Huang, H. and Leung, L. (2009), 'Instant messaging addiction among teenagers in China: Shyness, alienation, and academic performance decrement', Cyberpsychology \& Behavior, Vol. 12 No. 6, pp. 675-679.

http://doi.org/10.1089/cpb.2009.0060

Hussein, R.M.S. and Hassan, S. (2017), 'Customer engagement on social media: how to enhance continuation of use', Online Information Review, Vol. 41 No. 7, pp. 1006-1028.

http://doi.org/10.1108/OIR-02-2016-0047

Jacques, R., Preece, J. and Carey, T. (1995), 'Engagement as a design concept for multimedia', Canadian Journal of Learning and Technology, Vol. 24 No. 1, pp. 49-59.

https://doi.org/10.21432/T2VG77

Jennett, C., Cox, A.L., Cairns, P., Dhoparee, S., Epps, A., Tijs, T. and Walton, A. (2008), 'Measuring and defining the experience of immersion in games', International Journal of Human-Computer Studies, Vol. 66 No. 9, pp. 641-661.

http://dx.doi.org/10.1016/j.ijhcs.2008.04.004 
Jiang, G. and Deng, W. (2011), 'An empirical analysis of factors influencing the adoption of Mobile Instant Messaging in China', International Journal of Mobile Communications, Vol. 9 No. 6, pp. 563583.

http://doi.org/10.1504/IJMC.2011.042777

Julien, H. and Michels, D. (2004), 'Intra-individual information behaviour in daily life', Information Processing and Management, Vol. 40 No. 3, pp. 547-562.

https://doi.org/10.1016/S0306-4573(02)00093-6

Kaplan, A.M. and Haenlein, M. (2010),'Users of the world, unite! The challenges and opportunities of social media', Business Horizon, Vol. 53 No. 1, pp. 59-68.

https://doi.org/10.1016/j.bushor.2009.09.003

Kapoor, K.K., Tamilmani, K., Rana, N.P., Patil, P., Dwivedi, Y.K. and Nerur, S. (2018), 'Advances in social media research: Past, present, and future', Information Systems Frontiers, Vol. 20 No. 3, pp. 531-558.

https://doi.org/10.1007/s10796-017-9810-y

Kappelman, L.A. (1995), 'Measuring user involvement: A diffusion of innovation perspective', Database Advances, Vol. 26 No. 2/3, pp. 65-86.

https://doi.org/10.1145/217278.217286

Kaye, L.K. and Quinn, S. (2020), 'Psychosocial outcomes associated with engagement with online chat systems', International Journal of Human-Computer Interaction, Vol. 36 No. 2, pp. 190-198.

https://doi.org/10.1080/10447318.2019.1620524

Kim, K.S., Sin, S.C.J. and Yoo-Lee, E.Y. (2014), 'Undergraduates' use of social media as information sources', College \& Research Libraries, Vol. 75 No. 4, pp. 442-457.

https://doi.org/10.5860/crl.75.4.442 
Kim, Y., Sohn, D. and Choi, S.M. (2011), 'Cultural difference in motivations for using social network sites: A comparative study of American and Korean college students', Computers in Human Behavior, Vol. 27 No. 1, pp. 365-372.

https://doi.org/10.1016/j.chb.2010.08.015

Korhan, O. and Ersoy, M. (2016), 'Usability and functionality factors of the social network site application users from the perspective of uses and gratification theory', Quality \& Quantity, Vol. 50 No. 4, pp. 1799-1816.

https://doi.org/10.1007/s11135-015-0236-7

Koufaris, M. (2002), 'Applying the technology acceptance model and flow theory to online consumer behaviour', Information Systems Research, Vol. 13 No. 2, pp. 205-223.

http://doi.org/10.1287/isre.13.2.205.83

Krippendorff, K. (2013), Content analysis: An introduction to its methodology, Sage, Thousand Oaks.

Kuhlthau, C.C. (2004), Seeking meaning: A process approach to library and information services, Libraries Unlimited, Westport.

http://dx.doi.org/10.1108/02640470810864208

Lalmas, M., O'Brien, H.L. and Yom-Tov, E. (2014), 'Measuring user engagement', Synthesis Lectures on Information Concepts, Retrieval, and Services, Vol. 6 No. 4, pp. 1-132.

http://dx.doi.org/10.2200/S00605ED1V01Y201410ICR038

Laurel, B. (1991), Computers as theatre, Addison-Wesley, Reading, MA.

Lehmann, J., Castillo, C., Lalmas, M. and Baeza-Yates, R. (2017), 'Story-focused reading in online news and its potential for user engagement', Journal of the Associaton for Information Science and Technology, Vol. 68 No. 4, pp. 869-883.

http://dx.doi.org/10.1002/asi.23707 
Lehmann, J., Lalmas, M., Yom-Tov, E. and Dupret, G. (2012), 'Models of user engagement', in Masthoff, J. and Mobasher, B. (Ed.s), Proceedings of the 20th international conference on user modeling, adaptation, and personalization, Springer, Berlin, pp. 164-175.

http://dx.doi.org/10.1007/978-3-642-31454-4_14

Li, D., Chau, P.Y.K. and Lou, H. (2005), 'Understanding individual adoption of instant messaging: An empirical investigation', Journal of the Association for Information Systems, Vol. 6 No. 4, pp. 102-129.

Lien, C.H. and Cao, Y. (2014), 'Examining WeChat users' motivations, trust, attitudes, and positive word-of-mouth: Evidence from China', Computers in Human Behavior, Vol. 41, pp. 104-111.

http://doi.org/10.1016/j.chb.2014.08.013

Liu, I.L.B., Cheung, C.M.K. and Lee, M.K.O. (2016), 'User satisfaction with microblogging: Information dissemination versus social networking', Journal of the Association for Information Science and Technology, Vol. 67 No. 1, pp. 56-70.

https://doi.org/10.1002/asi.23371

Logan, R.J. (1994), 'Behavioral and emotional usability: Thomson consumer electronics', Wiklund, M. (Ed.), Usability in practice: How companies develop user-friendly products, Academic Press, London, pp. 59-82.

Lopatovska, I. (2014), 'Toward a model of emotions and mood in the online information search process', Journal of the Association for Information Science and Technology, Vol. 65 No. 9, pp. 1775-1793.

https://doi.org/10.1002/asi.23078

Lopatovska, I. and Arapakis, I. (2011), 'Theories, methods and current research on emotions in library and information science, information retrieval and human-computer interaction', Information Processing and Management, Vol. 47 No. 4, pp. 575-592.

https://doi.org/10.1016/j.ipm.2010.09.001

Lu, Y., Zhou, T. and Wang, B. (2009), 'Exploring Chinese users' acceptance of instant messaging using the theory of planned behavior, the technology acceptance model, and the flow theory', Computers in Human Behavior, Vol. 25 No. 1, pp. 29-39. 
http://doi.org/10.1016/j.chb.2008.06.002

Mauri, M., Cipresso, P., Balgera, A., Villamira, M. and Riva, G. (2011), 'Why is Facebook so successful? Psychophysiological measures describe a core flow state while using Facebook', Cyberpsychology, Behavior and Social Networking, Vol. 14 No. 12, pp. 723-731.

https://doi.org/10.1089/cyber.2010.0377

McCay-Peet, L., Lalmas, M. and Navalpakkam, V. (2012), 'On saliency, affect and focused attention', in Konstan, J.A. (Ed.), Proceedings of the SIGCHI Conference on Human Factors in Computing Systems, ACM, New York, pp. 541-550.

https://doi.org/10.1145/2207676.2207751

McCay-Peet, L. and Quan-Haase, A. (2016), 'A model of social media engagement: User profiles, gratifications, and experiences', O'Brien, H. and Cairns, P. (Ed.s), Why engagement matters: Crossdisciplinary perspectives of user engagement in digital media, Springer, Cham, pp. 199-216.

http://doi.org/10.1007/978-3-319-27446-1_9

Nguyen, D.T. and Fussell, S.R. (2016), 'Effects of conversational involvement cues on understanding and emotions in instant messaging conversations', Journal of Language and Social Psychology, Vol. 35 No. 1, pp. 28-55.

https://doi.org/10.1177/0261927X15571538

Nielsen, J. (1993), Usability engineering, AP Professional, New York.

Nwokedi, V.C. (2019), 'Use of social networking sites among undergraduates: A case study of Department of Theater and Film Arts, Faculty of Arts, University of Jos, Jos, Nigeria', Library Philosophy and Practice (e-journal), 2236.

O'Brien, H.L. (2017), 'Antecedents and learning outcomes of online news engagement', Journal of the Association for Information Science and Technology, Vol. 68 No. 12, pp. 2809-2820.

http://dx.doi.org/10.1002/asi.23854 
O'Brien, H.L. (2016), 'Theoretical perspectives on user engagement', O'Brien, H. and Cairns, P. (Ed.s), Why engagement matters: Cross-disciplinary perspectives of user engagement in digital media, Springer, Cham, pp. 1-26.

http://doi.org/10.1007/978-3-319-27446-1_1

O'Brien, H.L. (2011), 'Exploring user engagement in online news interactions', Proceedings of the American Society for Information Science and Technology, Vol. 48 No. 1, pp. 1-10.

https://doi.org/10.1002/meet.2011.14504801088

O'Brien, H.L. (2010), 'The influence of hedonic and utilitarian motivations on user engagement: The case of online shopping experiences', Interacting with Computers, Vol. 22 No. 5, pp. 344-352.

https://doi.org/10.1016/j.intcom.2010.04.001

O'Brien, H.L., Cairns, P. and Hall, M. (2018), 'A practical approach to measuring user engagement with the refined user engagement scale (UES) and new UES short form', International Journal of Human Computer Studies, Vol. 112, pp. 28-39.

https://doi.org/10.1016/j.ijhcs.2018.01.004

O'Brien, H.L. and Lebow, M. (2013), 'A mixed methods approach to measuring user experience in online news interactions', Journal of the Association for Information Science and Technology, Vol. 64 No. 8, pp. 1543-1556.

https://doi.org/10.1002/asi.22871

O'Brien, H.L. and Toms, E.G. (2013), 'Examining the generalizability of the User Engagement Scale (UES) in exploratory search', Information Processing and Management, Vol. 49 No. 5, pp. 1092-1107. https://doi.org/10.1016/j.ipm.2012.08.005

O'Brien, H.L. and Toms, E.G. (2010), 'The development and evaluation of a survey to measure user engagement', Journal of the American Society for Information Science and Technology, Vol. 61 No. 1, pp. 50-69.

https://doi.org/10.1002/asi.21229 
O'Brien, H.L. and Toms, E.G. (2008), 'What is user engagement? A conceptual framework for defining user engagement with technology', Journal of the Association for Information Science and Technology, Vol. 59 No. 6, pp. 938-955.

http://dx.doi.org/10.1002/asi.20801

Olsen, D.R. (1992), User interface management systems, Morgan-Kaufman, San Mateo, CA.

Overbeeke, K., Djajadiningrat, T., Hummels, C. and Wensveen, S. (2002). 'Beauty in usability: Forget about ease of use!', Green W.S. and Jordan, P.W. (Eds.), Pleasure with products: Beyond usability, Taylor \& Francis, London, pp. 9-18.

Reynolds, R. and Chiu, M.M. (2016), 'Reducing digital divide effects through student engagement in coordinated game design, online resource use, and social computing activities in school', Journal of the Association for Information Science and Technology, Vol. 67 No. 8, pp. 1822-1835.

http://dx.doi.org/10.1002/asi.23504

Rouibah, K. (2008), 'Social usage of instant messaging by individuals outside the workplace in Kuwait: A structural equation model', Information Technology \& People, Vol. 21 No. 1, pp. 34-68.

http://doi.org/10.1108/09593840810860324

Russell, J.A. (1994), 'Is there universal recognition of emotion from facial expression? A review of the cross-cultural studies', Psychological Bulletin, Vol. 115 No. 1, pp. 102-141.

https://doi.org/10.1037/0033-2909.115.1.102

Scherer, K.R. (2005), 'What are emotions? And how can they be measured?', Social Science Information, Vol. 44 No. 4, pp. 695-729.

http://doi.org/10.1177/0539018405058216

Scherer, K.R. (2001), 'Emotions, psychological structure of', Smelser, N. J. and Baltes, P. B. (Ed.s.), International Encyclopedia of the Social \& Behavioral Sciences, Elsevier, Oxford, pp. 4472-4477.

http://doi.org/10.1016/B0-08-043076-7/01711-3 
Skelly, T., Fries, K., Linnett, B., Nass, C. and Reeves, B. (1994), 'Seductive interfaces: Satisfying a mass audience', in Plaisant, C. (Ed.), ACM CHI'94: Conference Companion on Human Factors in Computing Systems, ACM, New York, pp. 359-360.

https://doi.org/10.1145/259963.260452

Slater, M., Usoh, M. and Steed, A. (1994), 'Depth of presence in virtual environments', Presence: Teleoperators and Virtual Environments, Vol. 3 No. 2, pp. 130-144.

http://doi.org/10.1162/pres.1994.3.2.130

Smock, A.D., Ellison, N.B., Lampe, C. and Wohn, D.Y. (2011), 'Facebook as a toolkit: A uses and gratification approach to unbundling feature use', Computers in Human Behavior, Vol. 27 No. 6, pp. 2322-2329.

https://doi.org/10.1016/j.chb.2011.07.011

Statista (2020), 'Most popular social networks worldwide as of July 2020, ranked by number of active users', available at: https://www.statista.com/statistics/272014/global-social-networks-ranked-bynumber-of-users/ (accesed 19 November 2020).

Sullivan, Y.W. and Koh, C.E. (2019), 'Social media enablers and inhibitors: Understanding their relationships in a social networking site context', International Journal of Information Management, Vol. 49, pp. 170-189.

Taipale, S. and Farinosi, M. (2018), 'The big meaning of small messages: The use of WhatsApp in intergenerational family communication', in Zhou, J. and Salvendy, G. (Eds.), Human aspects of IT for the aged population. Acceptance, communication and participation: 4th. International Conference ITAP 2018, Springer, Cham, pp. 532-546.

https://doi.org/10.1007/978-3-319-92034-4_40

Teo, T.S.H., Lim, V.K.G. and Lai, R.Y.C. (1999), 'Intrinsic and extrinsic motivation in internet usage', Omega, Vol. 27 No. 1, pp. 25-37.

https://doi.org/10.1016/S0305-0483(98)00028-0

Tullis, T.S. (1988), 'Screen design', Helander, M. (Ed.), Handbook of Human-Computer Interaction, North-Holland, New York, pp. 377-411. 
Turel, O., Brevers, D. and Bechara, A. (2018), 'Time distortion when users at-risk for social media addiction engage in non-social media tasks', Journal of Psychiatric Research, Vol. 97, pp. 84-88.

http://doi.org/10.1016/j.jpsychires.2017.11.014

Van Meter, K.M. (1990), 'Methodological and design issues: Techniques for assessing the representatives of snowball samples', NIDA Research Monograph, Vol. 98, pp. 31-43.

Venkatesh, V. and Bala, H. (2008), 'Technology acceptance model 3 and a research agenda on interventions', Decision Science, Vol. 39 No. 2, pp. 273-315.

https://doi.org/10.1111/j.1540-5915.2008.00192.x

Venkatesh, V., Morris, M.G., Davis, G.B. and Davis, F.D. (2003), 'User acceptance of information technology: Toward a unified view', MIS Quarterly, Vol. 27 No. 3, pp. 425-478.

http://doi.org/10.2307/30036540

Venkatesh, V., Thong, J.Y. and Xu, X. (2012), 'Consumer acceptance and use of information technology: Extending the unified theory of acceptance and use of technology', MIS Quarterly, Vol. 36 No. 1, pp. 157-178.

http://doi.org/10.2307/41410412

Wang, C., Hsu, Y. and Fang, W. (2004), 'Acceptance of technology with network externalities: An empirical study of internet instant messaging services', Journal of Information Technology Theory and Application (JITTA), Vol. 6 No. 4, pp. 15-28.

Wang, W., Hsieh, J.J. and Song, B. (2012), 'Understanding user satisfaction with Instant Messaging: An empirical survey study', International Journal of Human-Computer Interaction, Vol. 28 No. 3, pp. 153-162.

http://doi.org/10.1080/10447318.2011.568893

Wang, W., Ngai, E. and Wei, H. (2012a), 'Explaining instant messaging continuance intention: The role of personality', International Journal of Human-Computer Interaction, Vol. 28 No. 8, pp. 500-510. 
https://doi.org/10.1080/10447318.2011.622971

Watson, D., Clark, L. and Tellegen, A. (1988), 'Development and validation of brief measures of positive and negative affect: The PANAS scales', Journal of Personality and Social Psychology, Vol. 54 No. 6, pp. 1063-1070.

https://doi.org/10.1037/0022-3514.54.6.1063

Watts, S. and Wyner, G. (2011), 'Designing and theorizing the adoption of mobile technology-mediated ethical consumption tools', Information Technology \& People, Vol. 24 No. 3, pp. 257-280.

https://doi.org/10.1108/09593841111158374

Wen-Shan, L., Hong-Ren, C., Hsieh, T. and Feng, J.Y. (2019), 'Role of social anxiety on high engagement and addictive behavior in the context of social networking sites', Data Technologies and Applications, Vol. 53 No. 2, pp. 156-170.

http://doi.org/10.1108/DTA-09-2018-0076

Whiteside, J., Bennett, J. and Holtzblatt, K. (1988), 'Usability engineering: Our experience and evolution', Helander, M. (Ed.), Handbook of Human-Computer Interaction, Elsevier, Amsterdam, pp. 791-817.

Witmer, B.G. and Singer, M.J. (1998), 'Measuring presence in virtual environments: A presence questionnaire', Presence, Vol. 7 No. 3, pp. 225-240.

http://dx.doi.org/10.1162/105474698565686

Xu, C., Ryan, S., Prybutok, V. and Wen, C. (2012), 'It is not for fun: An examination of social network site usage', Information \& Management, Vol. 49 No. 5, pp. 210-217.

https://doi.org/10.1016/j.im.2012.05.001

Yoon, C., Jeong, C. and Rolland, E. (2015), 'Understanding individual adoption of mobile instant messaging: A multiple perspectives approach', Information Technology and Management, Vol. 16 No. 2, pp. 139-151.

http://doi.org/10.1007/s10799-014-0202-4 
Yu, J. (2014), 'We look for social, not promotion: Brand post strategy, consumer emotions, and engagement -- A case study of the Facebook brand pages', GSTF Journal on Media \& Communications, Vol. 1 No. 2, pp. 32-41.

Zaman, M., Ananda rajan, M. and Dai, Q. (2010), 'Experiencing flow with instant messaging and its facilitating role on creative behaviors', Computers in Human Behavior, Vol. 26 No. 5, pp. 1009-1018. http://doi.org/10.1016/j.chb.2010.03.001

Zhou, T., Li, H. and Liu, Y. (2015), 'Understanding mobile IM continuance usage from the perspectives of network externality and switching costs', International Journal of Mobile Communications, Vol. 13 No. 2, pp. 188-203.

http://doi.org/10.1504/IJMC.2015.067963

Zhou, T. and Lu, Y. (2011), 'Examining mobile instant messaging user loyalty from the perspectives of network externalities and flow experience', Computers in Human Behavior, Vol. 27 No. 2, pp. 883-889.

http://doi.org/10.1016/j.chb.2010.11.013

Zong, W., Yang, J. and Bao, Z. (2019), 'Social network fatigue affecting continuance intention of social networking services', Data Technologies and Applications, Vol. 53 No. 1, pp. 123-139.

https://doi.org/10.1108/DTA-06-2018-0054 
Table I. Participants' demographics

\begin{tabular}{|c|c|c|c|c|c|c|}
\hline Variable & $\begin{array}{l}\text { Family } \\
\text { unit } \\
\text { group } \\
\text { chat }\end{array}$ & $\begin{array}{l}\text { Broader } \\
\text { family } \\
\text { group } \\
\text { chat }\end{array}$ & $\begin{array}{l}\text { Friends } \\
\text { from } \\
\text { adolescence } \\
\text { group chat }\end{array}$ & $\begin{array}{l}\text { Current } \\
\text { friends } \\
\text { group } \\
\text { chat }\end{array}$ & $\begin{array}{l}\text { Class } \\
\text { group } \\
\text { chat }\end{array}$ & $\begin{array}{l}\text { Professor } \\
\text { group } \\
\text { chat }\end{array}$ \\
\hline $\begin{array}{r}\text { Gender } \\
\text { Male } \\
\end{array}$ & 1 & 2 & -- & 3 & 5 & 3 \\
\hline Female & 2 & 3 & 3 & 4 & 4 & -- \\
\hline $\begin{array}{c}\text { Age in years } \\
10<x<30\end{array}$ & 2 & 1 & -- & 4 & 9 & -- \\
\hline $30<x<50$ & -- & 2 & -- & 2 & -- & 2 \\
\hline$x>50$ & 1 & 2 & 3 & 1 & -- & 1 \\
\hline $\begin{array}{l}\text { Residence } \\
\text { location } \\
\text { City }\end{array}$ & 3 & -- & 2 & 7 & 9 & 3 \\
\hline Town & -- & 4 & 1 & -- & -- & -- \\
\hline Rural area & -- & 1 & -- & -- & -- & -- \\
\hline $\begin{array}{l}\text { Education } \\
\text { Primary } \\
\text { education }\end{array}$ & -- & 1 & -- & -- & -- & -- \\
\hline $\begin{array}{l}\text { Secondary } \\
\text { education }\end{array}$ & -- & -- & -- & -- & 9 & -- \\
\hline Undergraduate & 2 & 3 & -- & 3 & -- & -- \\
\hline $\begin{array}{l}\text { Graduate } \\
\text { degree }\end{array}$ & 1 & 1 & 3 & 4 & -- & 3 \\
\hline $\begin{array}{l}\text { Primary } \\
\text { Occupation } \\
\text { Student }\end{array}$ & 2 & 1 & -- & 3 & 9 & -- \\
\hline Education & 1 & -- & 2 & -- & -- & 3 \\
\hline $\begin{array}{c}\text { Public } \\
\text { Administration }\end{array}$ & -- & 1 & 1 & 1 & -- & -- \\
\hline Trade, services & -- & 1 & -- & 1 & -- & -- \\
\hline $\begin{array}{l}\text { Private } \\
\text { company }\end{array}$ & - & 2 & -- & 2 & -- & -- \\
\hline
\end{tabular}

Table II. Long-term engagement from a cognitive perspective

\begin{tabular}{|l|l|l|l|}
\hline Factors & $\begin{array}{l}\text { Intensity level } \\
\text { (overall assessment) }\end{array}$ & Examples & Features \\
\hline $\begin{array}{l}\text { PE } \\
\text { (perceived } \\
\text { enjoyment) }\end{array}$ & Moderate to high & $\begin{array}{l}\text { *S21 (man,18 years } \\
\text { old): "There are } \\
\text { some group chats in } \\
\text { which you laugh a } \\
\text { lot" }\end{array}$ & $\begin{array}{l}\text { * Does not trigger } \\
\text { the use of } \\
\text { WhatsApp, this } \\
\text { characteristic } \\
\text { emerges } \\
\text { additionally. }\end{array}$ \\
& $\begin{array}{l}\text { *S4 (woman,46 } \\
\text { years old): "There is } \\
\text { always a group chat }\end{array}$ & \\
\hline
\end{tabular}




\begin{tabular}{|c|c|c|c|}
\hline & & $\begin{array}{l}\text { in which someone } \\
\text { sends something } \\
\text { entertaining or says } \\
\text { something funny" }\end{array}$ & $\begin{array}{l}* \text { Most frequently } \\
\text { perceived in friend } \\
\text { group chats }\end{array}$ \\
\hline $\begin{array}{l}\text { PU } \\
\text { (perceived } \\
\text { usefulness) }\end{array}$ & Very high & $\begin{array}{l}\text { *S16 (man,18 years } \\
\text { old): "I personally } \\
\text { think WhatsApp is } \\
\text { very useful" } \\
\text { *S7 (woman,51 } \\
\text { years old): "Speaking } \\
\text { of WhatsApp in } \\
\text { terms of it being } \\
\text { useful, it makes you } \\
\text { feel like you've } \\
\text { solved something" }\end{array}$ & $\begin{array}{l}\text { * Used in the } \\
\text { management and } \\
\text { solving of simple } \\
\text { daily life tasks } \\
\text { * Characteristic } \\
\text { pointed out in any } \\
\text { age and primary } \\
\text { occupation }\end{array}$ \\
\hline $\begin{array}{l}\text { PEOU } \\
\text { (perceived ease } \\
\text { of use) }\end{array}$ & Very high & $\begin{array}{l}\text { *S24 (man,16 years } \\
\text { old): "It is also pretty } \\
\text { easy to use" } \\
\text { *S12 (woman,53 } \\
\text { years old): "It's just } \\
\text { that it's so easy that } \\
\text { you get hooked very } \\
\text { easily" }\end{array}$ & $\begin{array}{l}\text { * Very easy to install } \\
\text { and to learn to use, } \\
\text { which greatly } \\
\text { facilitates its use by } \\
\text { older people } \\
\text { * The ease of use is } \\
\text { perceived as cause } \\
\text { of } \\
\text { misunderstandings } \\
\text { and addiction }\end{array}$ \\
\hline
\end{tabular}

Table III. Engaging interaction from a cognitive perspective

\begin{tabular}{|c|c|c|c|}
\hline Factors & $\begin{array}{l}\text { Intensity level } \\
\text { (overall assessment) }\end{array}$ & Examples & Features \\
\hline Time awareness & Moderate to high & $\begin{array}{l}\text { *S11 (man, } 22 \text { years } \\
\text { old): "Then, when } \\
\text { it's over [the } \\
\text { WhatsApp } \\
\text { conversation], you } \\
\text { think: How long have } \\
\text { I spent, it's been } \\
\text { three hours" } \\
\text { *S3 (woman,52 } \\
\text { years old): “I don't } \\
\text { feel like I lose } \\
\text { awareness of time or } \\
\text { space, not a lot. } \\
\text { There is always } \\
\text { something, but no... } \\
\text { no" }\end{array}$ & $\begin{array}{l}\text { * All three factors } \\
\text { depend on the } \\
\text { importance of the } \\
\text { conversation. The } \\
\text { more importance } \\
\text { that the } \\
\text { conversation has for } \\
\text { the user, the less } \\
\text { aware he or she will } \\
\text { be of the passing of } \\
\text { time or what } \\
\text { happens around him } \\
\text { or her, and the } \\
\text { bigger the focus in } \\
\text { the conversation will } \\
\text { be }\end{array}$ \\
\hline
\end{tabular}




\begin{tabular}{|c|c|c|c|}
\hline $\begin{array}{l}\text { Awareness of } \\
\text { surroundings }\end{array}$ & Moderate to high & $\begin{array}{l}\text { *S22 (man,15 years } \\
\text { old): "When you're } \\
\text { paying attention to } \\
\text { WhatsApp you } \\
\text { usually don't realize } \\
\text { what's going on } \\
\text { around you" } \\
\text { *S28 (woman, } 25 \\
\text { years old): "When } \\
\text { I'm doing something } \\
\text { it's the same for me } \\
\text { [...] I wasn't very } \\
\text { aware of what } \\
\text { happened around } \\
\text { me" }\end{array}$ & $\begin{array}{l}\text { * All three factors } \\
\text { are related, so the } \\
\text { increase in attention } \\
\text { focusing implies } \\
\text { decrease in } \\
\text { awareness and vice } \\
\text { versa } \\
\text { * The usually low } \\
\text { levels in these } \\
\text { factors are related to } \\
\text { doing any other daily } \\
\text { activity while } \\
\text { simultaneously } \\
\text { keeping up with } \\
\text { conversations in }\end{array}$ \\
\hline $\begin{array}{l}\text { Absorption of } \\
\text { attention }\end{array}$ & Low to very low & $\begin{array}{l}\text { *S6 (man, } 47 \text { years } \\
\text { old): “I think I'm not } \\
\text { [I'm not focused], } \\
\text { because I haven't } \\
\text { had any extremely } \\
\text { urgent cases" } \\
\text { *S11 (man, } 22 \text { years } \\
\text { old): "I paid more } \\
\text { attention in the } \\
\text { upsetting } \\
\text { experience, because } \\
\text { they are more } \\
\text { important issues. In } \\
\text { the other one, a little } \\
\text { less, because it's a } \\
\text { little more trivial" }\end{array}$ & $\begin{array}{l}\text { WhatsApp, although } \\
\text { the level of } \\
\text { importance of the } \\
\text { conversation also } \\
\text { influences the level } \\
\text { of multitasking }\end{array}$ \\
\hline
\end{tabular}




\section{Abstract \\ Purpose}

The aim of this exploratory study is to analyze if the most used factors related to the engaging interaction and long-term engagement with online applications can be applied to WhatsApp in a context of everyday life and to investigate what parameters would best describe the engagement with WhatsApp in this context.

\section{Design/methodology/approach}

A qualitative method was employed to explore the cognitive, emotional, and behavioral factors that mainly comprise the experience of a user with an online application, both at a point in time and over time. Data from thirty semi-structured interviews and questionnaires from six group chats were collected and analyzed. The sample was made up of people from 13 to 58 years old.

\section{Findings}

Findings suggest that the factors used in this study to evaluate long-term engagement and engaging interactions with WhatsApp are relevant, except for cognitive factors related to engaging interactions, indicating that the cognitive point of view is more difficult to apply in the engaging interaction analysis. Other attributes related to information retrieval are suggested, best suited to the informative use of this tool.

\section{Originality/value}

Long-term engagement studies are scarcer concerning Mobile Instant Messaging applications. Regarding engagement interaction, its analysis focusing on WhatsApp has not been approached. This study suggests the convenience of using parameters related to information to evaluate the engaging interaction, according to the informative use of the application.

\section{Keywords}

WhatsApp, Engaging interaction, Long-term engagement, Emotional aspects, Cognitive aspects, Behavioral aspects, Qualitative methods

\section{Paper type}

Research paper 